\title{
LA AFECTACIÓN AL DERECHO HUMANO A RECIBIR INFORMACIÓN VERAZ OCASIONADO POR LOS POLÍTICOS EN SUS CAMPAÑAS ELECTORALES
}

THE AFFECTATION TO THE HUMAN RIGHT TO RECEIVE TRUTHFUL INFORMATION CAUSED BY POLITICIANS IN THEIR ELECTORAL CAMPAIGNS

\section{Iván Rodrigo Avalos Barreno*}

Resumen: En el Ecuador es común observar como cada cierto periodo de tiempo los políticos se comunican con el ciudadano elector por medio de grandes campañas publicitarias con el fin de lograr obtener un cargo en el sector público; el artículo analiza el significado del derecho a recibir información veraz, utilizando para ello el método teórico de inducción al partir del fenómeno jurídico político publicitario, para obtener premisas generales en pos de que el elector reciba información de calidad y no sea engañado por el candidato. El derecho a la información es abordado en el primer apartado para luego continuar con la información política en el Ecuador, posteriormente la información veraz es analizada, culminando con el diagnostico de algunas propuestas de campaña jamás llevadas a cabo. El trabajo concluye en que la información política que engaña al ciudadano es publicitada debido a la falta de regulación estatal lo cual provoca la vulneración del derecho de los ciudadanos a recibir una información veraz y verificada en la campaña política.

Palabras clave: Campaña política, derecho a la información, diligencia informativa, información veraz, ofertas electorales

\footnotetext{
* Abogado por la Pontificia Universidad Católica del Ecuador (Quito). Socio Fundador Estudio Jurídico A\&F. ivanro41@ hotmail.com
} 
Abstract: In Ecuador it is common to observe how politicians every certain time communicate with all the citizens throughout huge advertising campaigns in order to achieve a public sector position; this paper analyzes the meaning of the right to receive truthful information, using the induction method from the legal political advertising phenomenon to obtain general premises so that the voter receives quality information and don't be fooled by the candidate. The right to receive information is the porpoise of the first chapter, then continue with the political information in Ecuador, subsequently the veracity information is analyzed, culminating with the diagnostic of some campaign proposals never fulfilled. This paper concludes that the political information that deceives the citizen is publicized due to lack of state regulation, which causes an infringement of the citizens' rights to receive truthfully and verified information in the political campaign.

Keywords: Truthful Information, Politic Campaign, Electoral Offers, Right to Information, Informative Diligence

Sumario. I. Planteamiento general. II. El derecho a la información. III. La información política en el ecuador. IV. Información veraz. VI. Conclusiones. Referencias.

\section{Planteamiento general}

La gran mayoría de ciudadanos ecuatorianos han sido "victimas" de campañas electorales; seguramente al caminar por las calles de la ciudad han recibido afiches, trípticos, flyers, y demás difusión escrita por parte de personas afines a los partidos políticos; al prender su televisor posiblemente tuvieron que observar en más de una ocasión propagandas en donde los candidatos muestran su mejor sonrisa, al encender la radio se escuchan canciones populares de la época adaptadas al gusto del candidato, e incluso al utilizar las redes sociales la publicidad esta presente. Al parecer varios ámbitos de la vida cotidiana están inundados por spots publicitarios, pero ¿Es acaso suficiente un spot publicitario para informar fehacientemente al ciudadano e incentivar a que tome una decisión correcta en las urnas?

Según Carbonell (2008), los electores que están próximos a emitir su voto, tienen el pleno derecho a recibir ideas y propuestas de los candidatos, las cuales les permitan elegir correctamente una vez que estén ejerciendo su derecho al voto, es por ello que hay un interés ciudadano en escuchar, ver y analizar debates y propuestas, en lugar de tan solo estar expuestos a la 
mercadotecnia la cual no aporta ideas, simplemente ofrece slogans con canciones con un buen ritmo, o sonrisas fingidas.

La herramienta más utilizada por los candidatos políticos en tiempo de campaña electoral es el llamado spot publicitario el cual es un pequeño pero profundo mensaje que busca acaparar la atención del ciudadano de forma persuasiva y eminentemente agresiva; para Díaz y Alva (2016), la utilización de spots tiene como fin ocultar cierta información o resaltarla; esto causa correlativamente una desinformación en el ciudadano imposibilitando su mejor elección en las urnas.

Los diversos canales de comunicación como por ejemplo la radio y televisión en tiempo de campaña electoral difieren de los spots ya que están sujetos a la interpretación, edición y filtrado de quienes están llamados a elaborar la noticia, mientras que el spot permite tener un control absoluto por parte del emisor logrando así una comunicación directa con el ciudadano receptor de la información (Díaz \& Alva, 2016). Es por ello que en la actualidad el político utiliza el internet y las redes sociales para hacer campaña mediante spots, inclusive en mayor proporción que los clásicos medios de comunicación. En este sentido Bañuelos y Meneses (2009) afirman:

«Un mensaje emitido en una conferencia de prensa por un candidato, por ejemplo, es tratado por un editor y un reportero antes de ser publicado. En la red, el proceso comunicativo de la era análoga: emisor-medio-receptor se trastoca, dando lugar a una relación directa entre quien dice y quien lo recibe, prescindiendo así de un medio de comunicación profesional, articulando un modelo de comunicación horizontal en el que el receptor se convierte en el emisor, ya que a Internet la caracteriza la interactividad, es decir, la posibilidad de participación de los internautas, quienes no solo pueden participar sino compartir y personalizar los contenidos de su preferencia, gracias a las aplicaciones diversas, propias de la Web 2.0» (p. 10)

Los candidatos políticos usualmente al no encontrarse bien posicionados en las encuestas previas a las elecciones suelen recurrir a argucias en donde utilizan el spot publicitario no solamente para difundir una idea sesgada de sus propuestas a los ciudadanos, sino también para descreditar y atacar a sus principales contendientes.

Al respecto en el país de México ${ }^{1}$ varios autores han hecho un análisis de este tipo de spots que buscan desprestigiar al contrario político, sobre todo los existentes en contra del entonces candidato López Obrador quien ha sido víctima de esta clase de "campaña sucia", según Castañeda y Coutiño

\footnotetext{
${ }^{1}$ México ha desarrollado un marco normativo complejo el cual busca tutelar los derechos de los ciudadanos en busca de poner un límite a la gran cantidad de campaña sucia y spots publicitarios engañosos.
} 
(2016) estos son algunos de los spots publicitados en tiempo de campaña «López Obrador es un peligro para México; es mentira que Lopez Obrador creo 800000 empleos en el Distrito Federal, el modelo económico de Lopez Obrador es un fracaso en el DF; Lopez Obrador te quiere ver la cara» (p. 122).

En las últimas elecciones presidenciales ecuatorianas se pudo evidenciar al igual que lo suscitado en México, una gran cantidad de spots que pretendían restar votos al candidato de la oposición Guillermo Lasso Mendoza. En vallas publicitarias ubicadas en puntos estratégicos de diferentes ciudades del país, así como en los canales estatales de televisión era común encontrarse con mensajes como «Prohibido olvidar Lasso y el feriado bancario», «Guillermo Lasso fue parte del gobierno de Mahuad, juntos quebraron al país»; e incluso se obsequiaban CD's a los transeúntes ${ }^{2}$ en donde se podía observar una especie de documental que relataba la crisis que vivió el Ecuador a finales del silgo XX e inicios del siglo XXI; este documental buscaba que el ciudadano asociara la crisis directamente con el candidato presidenciable Guillermo Lasso.

Un acontecimiento de tal relevancia como es el hecho de escoger a un candidato quien llevara las riendas del país debería ser plenamente controlado por parte del Estado, de manera que el cuidado se sienta seguro al pensar que sus derechos están siendo tutelados. El investigador estadounidense John Ackerman (2013), afirma que se dejan de aplicar derechos cuando los electores no reciben información que les permita tomar una libre decisión debido a que no es suficiente que el organismo estatal de control garantice un conteo de votos fiable ${ }^{3}$, sino que debe también asegurar y garantizar el derecho a la libertad de expresión el cual no significa únicamente que cualquier persona tenga la posibilidad de emitir su opinión sino que los ciudadanos deben contar con información de calidad, es decir aquella que es veraz y verificada.

\section{EL DERECHO A LA INFORMACIÓN}

La parte dogmática de la Carta Magna establece varios derechos a los que el ciudadano tiene completo alcance mediante las garantías instauradas

\footnotetext{
${ }^{2}$ La campaña electoral del año 2017 en busca del Presidente del Ecuador puede pasar a la historia como una de las más controvertidas, debido sobre todo a que se utilizó todo el aparataje estatal para desprestigiar a los candidatos que no formaban parte del oficialismo.

${ }^{3}$ El Consejo Nacional Electoral en el Ecuador mediante su normativa trata ampliamente sobre la forma en la que se contaran los votos así como el gasto máximo que el político debe utilizar en su campaña, pero descuida lo referente al contenido informativo que la publicidad debe tener para ser emitida al ciudadano elector.
} 
por el Estado, al respecto la Constitución establece que todas las personas «en forma individual o colectiva, tienen derecho a: Buscar, recibir, intercambiar, producir y difundir información veraz, verificada, oportuna, contextualizada, plural, sin censura previa acerca de los hechos, acontecimientos y procesos de interés general, y con responsabilidad ulterior» (art.18, num.1).

Para comprender de la mejor forma posible lo que se debe entender por derecho a la información es necesario inicialmente especificar de manera rápida y precisa lo que es información.

Para Iván Ávalos (2019)

«La información es el conjunto de datos que contiene importancia ya sea jurídica, política, informativa, o en cualquier otro ámbito la cual se encuentra compilada o agrupada previamente por una persona o un grupo de personas que tienen interés en ello para que posteriormente pueda ser tanto transmitida o receptada por varios sujetos, y que tiene como principal objetivo o propósito el de infundir un mensaje que sirva para que la persona quien recepta la información ejerza una determinada acción. En el caso de la información política por ejemplo el mensaje es la oferta y promesa de campaña y la acción que busca que el receptor ejerza es que se emita el voto en favor del candidato» (p. 7).

Este conjunto de datos está revestido y protegido por un derecho, el derecho a la información, el cual según Villanueva (2008), puede ser definido como una rama del derecho público que tiene como objetivo estudiar las normas que regulan las relaciones de medios de comunicación con el Estado y la libertad de expresión con sus limitaciones ${ }^{4}$ y alcances.

El derecho a la información conforme lo expuesto por Gamarra (1995), está íntimamente ligado y es presupuesto del derecho a la participación ciudadana en sus diferentes manifestaciones que incluyen los referéndums, plebiscitos y consultas populares.

Llegar a obtener un significado del derecho a la información ha sido fruto de una larga evolución histórica ${ }^{5}$. Loreti (1995) afirma:

«El concepto que hoy entendemos como derecho universal a la información es el resultado de un devenir histórico que comienza por reconocer derechos a quienes son propietarios de las estructuras informativas, luego a quienes trabajan bajo la dependencia de éstos y finalmente a todos los hombres» (p. 4).

${ }^{4}$ Los límites a la libertad de expresión se han visto en la necesidad de evolucionar constantemente, debido sobre todo a las nuevas tecnologías de la información y al internet. ${ }^{5}$ En el siglo XIX solo podían ejercitar el derecho a la libertad de prensa aquellos quienes tenían los recursos necesarios para poder contar con sus propios medios y quienes contaban con estos recursos eran solamente los empresarios, de allí el nacimiento del término "prensa". 
El derecho a la información se ha convertido en una garantía esencial, elemental y básica para el ser humano, es decir aquello de lo que no puede prescindir para su vida diaria, es por ello que el art. 19 de la Declaración Universal de Derechos Humanos (1948) establece que todos tenemos derecho a la libertad de opinión y de expresión: «este derecho incluye el de no ser molestado a causa de sus opiniones, el de investigar y recibir informaciones y opiniones, y el de difundirlas, sin limitación de fronteras, por cualquier medio de expresión».

Para Durán, Añoveros y Astarloa (2011), al hablar de derechos humanos se está tratando directamente sobre bienes elementales de la persona, aquellos que debido a su relevancia requieren de un blindaje jurídico. El revestimiento por parte del derecho a estos elementos fundamentales para el ser humano mediante el aparataje estatal es lo que se conoce como derechos humanos.

La relevancia del derecho a la información en la actualidad se asemeja a la de otros derechos fundamentales, Nogueria (2000) sostiene que:

«El derecho del informado a conocer y saber los hechos y acontecimientos de relevancia pública y veraces que ocurren en el medio social es un elemento esencial que le posibilita ser un sujeto activo y un ciudadano participativo de la sociedad política de que se encuentra formado parte. El derecho a la información es de tanta relevancia en la sociedad contemporánea como el derecho a la educación» (p. 327).

La ciencia jurídica por intermedio de la normativa existente siempre protege a la parte más débil de una relación, por ejemplo el trabajador siempre tendrá una mayor protección frente al empleador, el consumidor contara con mayores prerrogativas en comparación al proveedor de bienes y servicios; en este orden de ideas en una campaña política la parte más débil es el ciudadano, quien está totalmente expuesto frente a la gran cantidad de publicidad, por lo cual merece la completa protección por parte de la ciencia jurídica.

Según lo señalado hasta el momento se puede colegir en breves rasgos que el derecho a la información es un derecho humano; el cual pretende que el ciudadano este protegido tanto en la información que recibe así como en aquella que emite, de manera que el derecho a la libertad de expresión se encuentre garantizado, pero ¿qué es lo que se debe entender por libertad de expresión?

El derecho a la libertad de expresión dentro de sí engloba a tres distintas posibilidades, o por llamarlo así contiene a tres sub-derechos; cada uno de ellos se complementa y constituye elemento fundamental de la libertad de expresión, estos son: (i) el ciudadano tiene la libertad de expresar 
libremente su opinión e información, con la garantía de no ser censurado o acallado por una persona particular o el Estado; (ii) la persona tiene la posibilidad de dotarse por sí mismo, así como seleccionar y elegir aquella información que creyese conveniente sin presión alguna que le conlleve a únicamente escoger tal o cual información; y, (iii) los ciudadanos disfrutan de la garantía de recibir una información que sea de calidad ${ }^{6}$.

Esta última posibilidad inserta dentro de la libertad de expresión así como consecuentemente dentro del derecho a la información es la más relevante en torno al presente trabajo en desarrollo, ya que recalca que el ciudadano debe recibir una información de calidad; pero ¿Acaso el ciudadano necesita información que contenga esta característica en todos los ámbitos informativos, o es necesario que la calidad este mayormente garantizada en ciertos momentos?

En consecuencia no toda la información es igualmente importante o relevante para los intereses comunes de los ciudadanos, es decir existe información deportiva, de entretenimiento, política, entre muchas otras, pero no puede asemejarse aquella información en donde se está discutiendo sobre el atuendo de las celebridades en la alfombra roja en comparación a la información política en donde se están socializando las propuestas de campaña de un candidato presidenciable.

Nuestra Constitución señala cuales son los momentos en los que el ciudadano necesariamente merece de una información de calidad. En concreto señala que el derecho consiste en: «buscar, recibir, intercambiar, producir y difundir información veraz, verificada, oportuna, contextualizada, plural, sin censura previa acerca de los hechos, acontecimientos y procesos de interés general, y con responsabilidad ulterior» (art.18, num.1).

Un hecho, acontecimiento y proceso de interés general evidentemente es una contienda política, en donde el ciudadano elector tiene la posibilidad de escoger a aquel representante quien tendrá a su cargo las decisiones más importantes para el porvenir de toda la nación. Es por ello que la información de calidad, es decir aquella que es veraz debe estar completamente garantizada en el tiempo de campaña electoral.

\footnotetext{
${ }^{6}$ La información de "calidad" es aquella que contempla todos los elementos que la norma establece; es decir aquella que es veraz, verificada, oportuna, plural, contextualizada y sin censura previa.
} 


\section{LA INFORMACIÓN POLÍTICA EN EL ECUADOR}

Para Valdez (2012) «las campañas electorales son procesos rutinarios en los sistemas políticos de impronta democrática, en las que dos o más candidatos y partidos políticos compiten por obtener el voto de los ciudadanos y así lograr un puesto de representación pública» (p. 135). La campaña política a más de verse plasmada en las diferentes formas de publicidad se la puede también encontrar en dadivas entregadas por el político al ciudadano elector.

La información vertida en campaña política se transforma en cortas historias de sencillo entendimiento para el elector, imposibilitando así entrar en el fondo del tema, considerando más importante entregar un mensaje ágil que evite el aburrimiento y llame mucho la atención; por esta razón la campaña política puede manipular la verdad e incluso mentir cínicamente al elector (Berrocal, 2005).

Un mensaje ágil y que sea de fácil entendimiento para el elector puede ser transmitido en cualquier medio de comunicación, sobre todo en las redes sociales y diferentes herramientas del internet las cuales en la actualidad están al alcance de gran parte de los ecuatorianos ${ }^{7}$. Holgado Gonzales (2017) afirma:

«No obstante, sin negar la relevancia de los medios de comunicación como la prensa, la radio y la televisión (...) no puede pasarse por alto el auge e impacto de las nuevas (ya no tan nuevas) tecnologías de la información y comunicación (medios digitales, redes sociales, blogs, etc.) han tenido en los últimos años, ofreciendo a los partidos políticos una valiosa vía de difusión de su mensaje y de participación ciudadana, con perfiles y dimensiones que no siempre proporcionan los medios tradicionales» (p. 459).

A pesar de que no es el tema del presente trabajo cabe señalar que la normativa del Ecuador, en palabras de Riofrío (2019) «dice poco sobre el tema de las redes sociales o sobre los aspectos digitales. En realidad, observamos que las normas vigentes no están pensadas para los nuevos medios de comunicación» (p. 3).

La mayoría de ciudadanos que están próximos a escoger a un candidato en las urnas no analizan el fondo de las propuestas publicitadas por el candidato ya sea en los medios de comunicación tradicionales, como la radio y televisión o en las diferentes herramientas de internet, de manera que el elector no hace un examen de la real posibilidad de que las propuestas

\footnotetext{
${ }^{7}$ Según estudios del Global Digital 2019 reports el uso de internet en el Ecuador a inicios del año 2019 alcanzo una penetración del 79\%, es decir que alrededor de 13.5 millones de ecuatorianos utilizan internet.
} 
y ofertas de campaña sean puestas en práctica a mediano o largo plazo, cosa que es aprovechada por el político populista quien basa su campaña en engaños.

En un estudio realizado en el vecino país de Colombia por las autoras Rivera y Suárez (2017), se logró obtener como conclusiones, después de analizar varias encuestas dirigidas a los electores, que el 92\% de los encuestados cree estar siendo manipulado en la campaña política; el 58\% de las personas cree tan solo parcialmente en la publicidad de campaña, el 33\% no cree absolutamente en dicha publicidad y tan solo un $9 \%$ asegura confiar en ella; mientras que el $70 \%$ considera que existe una saturación de propagada política ${ }^{8}$.

Para regular la campaña política electoral la Constitución nacional establece que «el Consejo Nacional Electoral tendrá, además de las funciones que determine la ley las siguientes: Controlar la propaganda y el gasto electoral, conocer y resolver sobre las cuentas que presenten las organizaciones políticas y los candidatos» (art. 219, num. 3). En base a este artículo el Consejo Nacional electoral es el organismo estatal competente el cual debería garantizar que el ciudadano elector reciba una información de calidad que le permita discernir entre los candidatos, tomando en cuenta sobre todo la veracidad en la información.

En este sentido el Consejo Nacional Electoral publico la Resolución 1-23-12-2015, la cual manda a que la información emitida en campaña electoral debe adecuarse a lo determinado en el art. $19 \$ 2$ de la Constitución, donde se establece que «se prohíbe la emisión de publicidad que induzca a la violencia, la discriminación, el racismo, la toxicomanía, el sexismo, la intolerancia religiosa o política y toda aquella que atente contra los derechos». Esta norma de remisión es el único límite que el político está obligado a observar antes de presentar su propaganda al público.

Considerando que la información política es un acontecimiento de interés general, es inaudito que el Ecuador establezca limites tan flexibles para el político en detrimento de los derechos del ciudadano, cosa que provoca la desinformación y demagogia política; es decir el político en tiempo de campaña está actuando conforme la normativa en el caso de que publicite una propuesta de imposible cumplimiento ${ }^{9}$ como por ejemplo

${ }^{8}$ Las autoras citadas realizaron encuestas a 324 electores de la ciudad de Bogotá, de diferentes estratos sociales y edades; este estudio además de las conclusiones expuestas en el presente trabajo arrojo resultados interesantes tales como que los comerciales en televisión son los preferidos por los votantes en pos de informarse acerca de los candidatos.

${ }^{9}$ Varias han sido las ofertas y propuestas de campaña publicitadas por los políticos las cuales a primera vista parecen ser muy difíciles e incluso imposibles de cumplir, basta con recordar la propuesta efectuada por el entonces candidato Álvaro Noboa con miras a ganar 
eliminar el impuesto al valor agregado y elevar el sueldo básico a mil dólares mensuales, siempre y cuando no utilice en su publicidad términos, imágenes o demás componentes que inciten a la violencia, discriminación, toxicomanía, etc.

El legislador nacional busco otra alternativa para poder normar la campaña política, para ello creo un cuerpo normativo específico que refiere sus lineamientos a lo que el político y su partido debe hacer en tiempo de elecciones.

«Todos los candidatos a Presidente (...) presentaran junto con el formulario de inscripción un plan de trabajo con al menos el siguiente contenido: 3. Plan de trabajo plurianual de acuerdo a la dignidad a la que hubieren optado, en el que se establecerán las propuestas y estrategias a ejecutarse de resultar electos» (Ley Orgánica Electoral, 2009, art. 97, num. 2).

El plan de trabajo plurianual que el político tiene la obligación de presentar no está sometido a una verificación ni calificación por parte del Consejo Nacional Electoral, institución que en pos de garantizar la correcta aplicación efectiva de los derechos de los ciudadanos debería tomar acciones concretas y específicas las cuales estén direccionadas a verificar fehacientemente si el plan de trabajo realizado por el político contiene información veraz y verificada; es decir si sus propuestas a materializarse en caso de llegar a ganar las elecciones son viables y están en capacidad de ser ejecutadas, o en su defecto carecen de sustento jurídico, económico y sociológico lo cual imposibilita su cumplimiento.

Para que el ciudadano elector este informado de la mejor manera posible, el Consejo Nacional Electoral tutelando el derecho a la información debería, una vez que el plan plurianual se encuentre revisado y calificado, socializar las propuestas de campaña así como la forma en la que estas van a ser cumplidas, utilizando para ello los medios de comunicación masivos.

Cabe señalar que la normativa ecuatoriana relacionada con temas político-electorales, a diferencia de lo que sucede en otros países principalmente europeos ${ }^{10}$, no ha tenido un avance progresivo tanto en lo que respecta al plan de trabajo que el político debe presentar así como la regulación de la campaña política.

la presidencia del año 2013, ofrecía a los electores construir un tren eléctrico semejante al metro para que cubra la ruta Tulcán-Riobamba, Quito-Esmeraldas y Esmeraldas Guayaquil. ${ }^{10}$ Los países que conforman la Unión Europea han desarrollado el llamado "Manual de Observancia Electoral de la Unión Europea", el cual en una de sus secciones trata ampliamente sobre la campaña electoral y la forma en la que esta debe ser transmitida a los ciudadanos electores. 


\section{INFORMACIÓN VERAZ}

Uno de los primordiales elementos que debe encontrarse presente en la información, para que esta se adecue a lo estipulado el artículo 19 de la Constitución es la veracidad. La Real Academia Española (2014) define "veraz" como: «que dice, usa o profesa siempre la verdad» (p. 510). Mientras que el Diccionario de la Lengua Española (2002) sostiene que verdad significa «conciencia de algo con el concepto de que ello forma la mente. Conformidad de lo que se dice con lo que se piensa. Cualidad de veraz» (p. 607).

El significado del término verdad va mucho más allá de lo que respecta a la ciencia jurídica; para poder llegar a su plena comprensión sería necesario utilizar a la filosofía y a la ética, pero ese no es el objetivo del presente trabajo, por lo cual será suficiente limitar este estudio a lo que se debe entender por verdad visto desde la especial óptica del derecho.

El Tribunal Constitucional de España en sus diversos fallos ha elaborado una estrategia muy útil para poder analizar si el requerimiento de la veracidad se encuentra plasmado en la información, al respecto Carreras, Vilajoana y Cuerva (2018), destacan los conceptos utilizados para la elaboración de sentencias por parte de este tribunal sistematizándolos en dos grandes apartados: la diligencia informativa y la realidad de los hechos narrados. Cabe señalar que según Azurmendi (2005), las disposiciones emitidas por el Tribunal son aplicables tanto a los profesionales de la comunicación, así como también a quienes no se han especializado en esta rama de la ciencia.

La diligencia informativa a su vez se subdivide en dos subconceptos; la actitud positiva del comunicador con respecto a la verdad y la comprobación razonable de los hechos que van a ser trasmitidos al ciudadano.

En cuanto a la actitud positiva del comunicador según lo dispuesto por el Tribunal Constitucional Español la información política emitida al público en tiempo de campaña electoral en donde se difunden propuestas realizables a futuro, debe adecuarse a la política actual así como a las proyecciones políticas a futuro; es decir un candidato antes de realizar un ofrecimiento debe analizar minuciosamente la realidad del país en la actualidad y lo que se espera suceda en el futuro; por ejemplo en nuestro país un indicador fiable seria el precio actual del petróleo, los informes técnicos del Banco Mundial así como las proyecciones futuras de la inflación.

Por su parte la comprobación razonable de los hechos se relaciona directamente con la garantía de cumplimiento de lo ofertado. Esto en la 
práctica se transforma en la existencia documentada del presupuesto que se planea utilizar para ejecutar la obra prometida así como demás informes de las diversas instituciones de control las cuales permitan afirmar que lo que se está ofertando va a ser posible de realizar.

El segundo gran apartado el cual según el Tribunal Constitucional de España sirve para comprender la veracidad en la información es la realidad de los hechos narrados. Al respecto según Ávalos (2019):

«A pesar de que es bastante subjetivo determinar la realidad de los hechos ya que para una persona el acercamiento a la realidad puede ser diferente del de otra, es necesario que por lo menos lo que se está informando a las personas responda a una objetividad de hechos palpables acontecidos, o que se espera que sucedan, sin alejarse de la realidad inmediata, es decir no se puede suponer que un hecho va a pasar en un futuro si es que los antecedentes facticos anteriores a este acontecimiento que se espera que suceda no están yendo de la mejor manera posible» (p. 15).

«Si la verdad absoluta no existe, el requisito de veracidad debe entenderse como la recta tendencia del informador hacia la averiguación de la realidad de los hechos y su leal trasmisión» (Merchante, 1995, p.109).

Es necesario para el mejor entendimiento de lo antedicho citar un ejemplo claro y común en la vida política nacional. El candidato presidencial $\mathrm{X}$ en tiempo de campaña electoral ofrece a los electores construir 500.000 casas al año, así como generar 300.000 empleos en el mismo periodo de tiempo, hace este ofrecimiento a sabiendas de que la tasa de desempleo es muy alta, la inmigración compromete la estabilidad del país, el precio del petróleo es bajo e inclusive el Banco Central estima que el producto interno bruto decaerá $2 \%$ el próximo año. En este caso el candidato estaría realizando una propuesta de campaña que no contiene una información veraz, por lo tanto engaña al ciudadano y deja de aplicar el derecho a la información.

\section{Propuestas de CAMPAÑa EFECTUAdas EN EL ECUADOR JAMÁS LLEVADAS A LA REALIDAD}

En nuestro país la regla general es que el político una vez que accede al poder después de ganar en las urnas olvide las propuestas ${ }^{11}$ que le ayudaron a obtener su curul, en este apartado se van a exponer los principales ofrecimientos efectuados por políticos los cuales demuestran como los

\footnotetext{
${ }^{11}$ Lenin Moreno llego a la presidencia del Ecuador en base a sus propuestas, una de ellas fue la de construir 325.000 casas para los más pobres, a poco más de un año de terminar su periodo solamente ha logrado construir 80.000 .
} 
electores son engañados provocando así que el derecho a recibir información veraz se vea totalmente afectado.

El ex presidente Rafael Correa Delgado en su última campaña electoral rumbo a la reelección como presidente del Ecuador recorría el país asegurando que en caso de ganar nuevamente las elecciones daría un giro de $180^{\circ}$ a la matriz productiva, ya que esta tendría sus cimientos en la energía eléctrica, para ello afirmaba que construiría 8 hidroeléctricas las cuales permitirían que en el país el precio de la electricidad disminuya notablemente e incluso se pueda exportar hacia países vecinos como Colombia y Perú. Con el fin de poder disfrutar de los beneficios de esta nueva matriz productiva aseveraba que era necesario dejar de lado las cocinas a gas para utilizar nuevas cocinas de inducción.

Efectivamente en base a esta y otras propuestas similares Correa ganó las elecciones e importó una gran cantidad de cocinas de inducción para que sean vendidas a los ciudadanos a precios bajos y con planes de financiamiento, plan que según Teleamazonas (2019) fracaso notablemente debido a la mala calidad del producto y a la falta de energía eléctrica que cubra la demanda

Según Ávalos (2019), la fecha en que Rafael Correa entregaría las 8 hidroeléctricas para el beneficio de todos los ecuatorianos era el año 2016, oferta totalmente incumplida ya que no se respetaron las fechas de construcción peor aún se entregó las 8 hidroeléctricas ofertadas; en la actualidad solamente funcionan 3 con muchos desperfectos que afecta su funcionamiento, con sobreprecios involucrando actos de corrupción. Al respecto el ministro de hidrocarburos Carlos Pérez dijo, las hidroeléctricas dependiendo de los tamaños tienen valores de $\$ 1.500$ a $\$ 1.700$ por megavatio, pero en nuestro caso algunas hidroeléctricas han costado $\$ 4.000$ por megavatio, El Universo (2018).

Para poder alcanzar la presidencia del país Lucio Gutiérrez ofertaba a los electores aumentar el sueldo a los maestros para que sus condiciones de vida mejoraran, prometía también a los ciudadanos mantener el precio de la gasolina y al diésel; una vez ya en el poder uno de sus primeros decretos presidenciales fue aumentar el precio de los combustibles; olvidó también la oferta de mejorar el sueldo de los maestros.

Estos ejemplos expuestos denotan la vulneración del derecho de los ciudadanos a recibir información veraz en la campaña política, revelando la falta de normativa nacional la cual sirva para exigir al político estudios técnicos que sirvan para justificar sus ofrecimientos. 


\section{CONCLUSIONES}

1. Los bienes elementales para el ser humano, es decir aquellos de los cuales el hombre no puede prescindir para su diario vivir, necesariamente deben estar garantizados por el Estado otorgándoles la jerarquía de derechos fundamentales; el derecho a la información debido a su total relevancia en la actualidad es considerado uno de ellos; por lo tanto la ciencia jurídica tiene la obligación de tutelarlo.

2. El derecho a la información se relaciona directamente con la libertad de expresión, la cual contiene dentro de sí tres diversas posibilidades o dicho de otro modo contempla a tres sub-derechos; uno de ellos conlleva a que el ciudadano tiene el derecho de contar con información de calidad, es decir aquella que es veraz.

3. La información de calidad que reúna el requisito de veracidad, debe estar garantizada en gran parte de los aspectos de la vida cotidiana del ciudadano, pero su tutela necesita un mayor grado de protección en aquellos acontecimientos de interés general, como lo es una campaña política en donde abunda la publicidad y el elector no está exento de ser engañado. .

4. La veracidad en la información política a la luz de lo expuesto por el Tribunal Constitucional de España puede ser determinada en base a dos requerimientos primordiales, la actitud positiva del comunicador la cual obliga al político a elaborar sus propuestas mediante el análisis de la realidad actual así como las proyecciones a futuro y la comprobación razonable de los hechos, es decir el fundamento de las ofertas de campaña en base a estudios técnicos sobre todo económicos y de presupuesto los cuales demuestren que es posible llevar a cabo lo ofertado.

5. El Código de la Democracia o Ley Orgánica Electoral no cumple su trabajo con el mero hecho de exigir al político un plan plurianual, debería obligar a que la institución competente como lo es el Consejo Nacional Electoral realice una debida calificación de este plan y lo someta a estudios en el ámbito económico, jurídico, ambiental, sociológico, con el fin de examinar profundamente su contenido, de modo que este plan plurianual se convierta en una verdadera herramienta en pos de aplicar el derecho a la información veraz para el elector.

6. Una vez que el plan plurianual se encuentre aceptado por el Consejo Nacional Electoral, esta institución está en la obligación de informar al ciudadano sobre la forma en la que las propuestas de campaña de cada candidato van a ser cumplidas a futuro, de esta manera la forma de hacer publicidad política cambiaria dejando de lado los spots y ataques entre 
políticos y centrándose más bien en aspectos tales como la posibilidad de llevar a la práctica lo ofertado.

7. Al parecer el Consejo Nacional Electoral ha agotado sus esfuerzos en normar lo concerniente al presupuesto que el político puede utilizar para su campaña electoral así como el tiempo en que la propaganda debe estar disponible para el ciudadano; pero olvida reglamentar lo referente al contenido de la propaganda electoral, provocando de esta forma que el derecho a que el ciudadano cuente con una información veraz deje de tutelarse.

8. Es necesario que la Ley Orgánica Electoral implemente un capítulo específico, el cual trate sobre sanciones hacia los políticos quienes no logren sustentar fehacientemente la forma en las que sus propuestas y ofertas de campaña publicitadas al ciudadano van a ser cumplidas en el caso de que logren ganar las elecciones; el castigo al candidato debe ser ejemplificativo llegando incluso en el peor de los casos a prohibir que continúe en la contienda política. Solo de esta manera se terminaría con la demagogia en el Ecuador.

\section{REFERENCIAS}

Ackerman, J. (2013). Instituciones electorales, derecho a la información y medios de comunicación durante las campañas presidenciales de 2012. Revista Mexicana de Ciencias Políticas y Sociales, 219(1), pp. 45-74

Añoveros, J., Durán, P., y Astarloa, I. (2011). La declaración universal de derechos humanos cumple 60 años. España: JM Bosch.

Avalos, I. (2019). El derecho de los ciudadanos a recibir una información veraz y verificada en la campaña política presidencial del Ecuador (tesis). Pontificia Universidad Católica de Ecuador Sede Ambato, Ambato.

Azurmendi, A. (2005). De la verdad informativa a la "información veraz" de la Constitución Española de 1978. Una reflexión sobre la verdad exigible desde el derecho a la información. Comunicación y Sociedad, 18(2), pp. 9-48. En https://dadun.unav.edu/bitstream/10171/8233/1/20090619094012.pdf

Bañuelos, J. \& Meneses, M. (2009). Internet y campañas electorales en México: la oportunidad postergada. En http://www.corteidh.or.cr/tablas/26853.pdf

Berrocal, G. (2005). La información política en la televisión: ¿apatía o interés entre los telespectadores? Comunicar, 25, pp. 1-10. En https://www.redalyc.org/articulo.oa? $\mathrm{id}=15825047$

Carbonell, M. (2008). La Libertad de expresión en materia electoral. Mexico: Tribunal Electoral del Poder Judicial de la Federeacion. 
Carreras, L., Vilajoana, S. \& Cuerva, J. (2018). ¿Cómo aplicar los límites jurídicos del periodismo? Barcelona: UOC.

Castañeda, E. \& Coutiño, P. (2016). Contenidos de los spots de los partidos políticos en campañas electorales en México. Un análisis de los efectos de las reformas electorales recientes. Tla-Melaua, 10(40), pp. 112-128. En http://www.scielo.org.mx/scielo.php?script=sci_arttext\&pid=S1870$69162016000200112 \& \operatorname{lng}=\mathrm{es} \& \operatorname{lng}=\mathrm{es}$

Díaz, O. \& Alva, M. (2016). El uso estratégico de la publicidad política de ataque en la elección federal intermedia de 2015 en México. Revista Mexicana de Opinión Pública, 21(1), pp. 33-49.

Gamarra, E. (1995). El derecho a la información. Themis, 32, pp. 81-93.

Holgado Gonzales, M. (2017). Publicidad e información sobre elecciones en los medios de comunicación durante la campaña electoral. Teoría y Realidad Constitucional, 40, pp. 457-485.

Loreti, D. (1995). El derecho a la información. Argentina: Paidós.

Real Academia Española (2014). Diccionario de la lengua española. Madrid: RAE.

Riofrío, J. (2019). El Impacto de los Nuevos Medios de Comunicación en la Campaña Electoral: Un Análisis Jurídico y Comunicacional. Revista de la Facultad de Jurisprudencia RFJ, 5, pp. 241-259. En

http://revistarfjpuce.edu.ec/index.php/rfj/article/view/164

Suárez, L. \& Rivera, E. (2017). Algunas percepciones y conductas de los electores sobre la comunicación política y el marketing político. Análisis: Revista colombiana de humanidades, 49(91), pp. 405-437.

Villanueva, E. (2008). Derecho de la información. Quito: Ciespal.

Valdez, A. (2012). El miedo y la ira como estrategia en las campañas electorales. Reflexión política, 14(27), pp. 134-140. 